\title{
A autoetnografia em pesquisas em Linguística Aplicada: reflexões do sujeito pesquisador/pesquisado
}

\author{
Fernando da Silva Pardo \\ Instituto Federal de São Paulo \\ fernando.pardo@ifsp.edu.br
}

\section{Resumo}

O objetivo deste artigo é ampliar a discussão acerca das implicações do uso da autoetnografia como metodologia de pesquisa em Linguística Aplicada, uma vez que se inscreve num paradigma pós-moderno e desafia a pesquisa científica canônica de base positivista. Nas páginas a seguir, procuro promover a reflexão crítica a partir da minha experiência pessoal como autoetnógrafo, durante a realização da minha pesquisa de doutorado, em que observei minhas próprias práticas enquanto professor de língua inglesa em uma escola pública de Ensino Fundamental-I, bem como busco problematizar os conflitos de identidade que surgem da experiência introspectiva do pesquisador/pesquisado nesta modalidade de investigação. Concluo que, apesar de ser alvo de críticas, a autoetnografia tem o potencial de promover o aprimoramento das práticas de ensino e aprendizagem realizadas nos próprios contextos observados, uma vez que nos fornece subsídios para que possamos promover transformações a partir da reflexão crítica acerca da nossa atuação na condição de professores/pesquisadores.

Palavras-chave: Autoetnografia; Metodologia de pesquisa; Identidades; Narrativas.

\begin{abstract}
This paper aims to broaden the discussion on the implications of the use of autoethnography as a research method in Applied Linguistics since its framework is under a postmodern paradigm and challenges the positivist canonical scientific research. On the following pages, I seek to promote critical reflection through my personal experience as an autoethnographer during my doctoral research, in which I observed my practices as an English teacher in a public elementary school, as well as to problematize the conflicts of identity that arise from the researcher/researched introspective experience in this methodology. I conclude that despite being criticized autoethnography has the potential to improve the teaching and learning practices in the contexts observed since it provides resources so that
\end{abstract}


we can promote transformations in our performance as teachers/researchers through critical reflection.

Keywords: Autoethnography; Research Methodology; Identities; Narratives.

\section{Introdução}

A escrita deste artigo surgiu a partir de uma necessidade observada ao longo da realização da minha tese de doutorado (PARDO, 2018), em que foi empregada como metodologia a pesquisa autoetnográfica, viés que transita entre a etnografia e a autobiografia (ELLIS; ADAMS; BOCHNER; 2011; ELLIS; BOCHNER, 2000), por meio de observações e autoobservações. Na ocasião da realização da pesquisa, entre os anos de 2013 a 2018, tive muitas dificuldades em encontrar publicações, em especial em língua portuguesa e no Brasil, as quais discutissem esta metodologia, o que me motivou a fazer uma revisão da literatura e refletir criticamente sobre o emprego desta modalidade de pesquisa a fim de auxiliar outros pesquisadores interessados no assunto. Apesar da recente publicação de um volume temático sobre o tema, em um periódico de grande relevância no meio acadêmico (PEREIRA; VIEIRA, 2018), observo que ainda há espaço para a problematização da autoetnografia, sobretudo a partir da perspectiva da Linguística Aplicada (doravante LA), com ênfase no ensino e aprendizagem de línguas.

Resumidamente, minha pesquisa de doutoramento buscou investigar em que medida as teorias de Letramentos (GEE, 2004; KALANTZIS; COPE, 2000; KRESS, 2003; LANKSHEAR; KNOBEL, 2006; MENEZES DE SOUZA, 2011a, 2011b; MONTE MÓR, 2013, 2014, 2018) seriam adequadas ou não ao ensino de inglês no Ensino Fundamental-I público, em uma escola de periferia, na região da grande São Paulo. Para tanto, busquei analisar uma proposta pedagógicoeducacional orientada pelas teorias de Letramentos, elaborada por mim e aplicada em minhas próprias turmas do $4^{\circ}$ e do $5^{\circ}$ ano do Ensino Fundamental-I, enquanto professor e pesquisador na escola investigada. Um dos objetivos foi examinar as epistemologias relacionadas às visões de ensino de língua daquele contexto, assim como problematizar outras maneiras de se abordar o ensino da língua inglesa de forma crítica e que levassem em consideração as especificidades dos indivíduos e do contexto investigado. Além disso, procurei observar o desenvolvimento do senso crítico, no que se refere aos alunos, e também as estratégias para o ensino 
de inglês e minha própria atuação como professor/pesquisador naquela proposta.

Portanto, o estudo supracitado pode ser definido como uma pesquisa qualitativa ou interpretativa do tipo [auto]etnográfica com ênfase na vida escolar cotidiana (ANDRÉ, 1995). Na abordagem etnográfica tradicional, segundo Lüdke e André (1986, p.26), o pesquisador precisa observar as situações presentes no cotidiano do contexto investigado por meio do contato direto, o que o auxiliará a compreender melhor as situações vivenciadas, a fim de buscar respostas para o problema formulado inicialmente. Por outro lado, no que tange à autoetnografia, Eriksson (2010, p. 93) defende que não se trata de adentrar o universo do outro, daquele que é diferente ou estranho para nós, mas de observar como nós mesmos e nossas práticas emergem a partir de determinado grupo ou contexto. Para ele, na etnografia o pesquisador é visto como um estranho, já na autoetnografia o pesquisador é familiar, posto que é membro do grupo pesquisado. Doloriert e Sambrook (2009) ressaltam ainda que pesquisar as próprias práticas tem algumas vantagens em termos de acessibilidade, custos e gerenciamento do estudo. Além disso, as autoras descrevem dois tipos de estudo autoetnográfico, sendo eles (1) o tipo "pesquisador-épesquisado" (p. 29) ${ }^{1}$, em que a investigação se constrói por meio de uma narrativa introspectiva na qual o indivíduo é o único participante do estudo, ou seja, a investigação se tornaria o que chamei de eutnografia. Como exemplo, cito uma narrativa em primeira pessoa em que Windle (2017) reflete sobre identidades sociais e ideologias linguísticas no Brasil, problematizando o conceito do falante nativo, a partir da sua visão enquanto imigrante para este país; e (2) o tipo "pesquisador- $e$-pesquisado" (DOLORIERT; SAMBROOK, 2009, p. 29)2, em que o indivíduo observa determinado grupo social ou cultura da qual ele também é membro. Assim, ressalto que a pesquisa de doutorado supracitada se inscreve nesta segunda perspectiva, já que o pesquisador é o observador de um grupo (salas de aula de inglês do Ensino Fundamental-I, em uma escola pública) do qual ele também faz parte (professor dos referidos alunos). Além disso, o estudo analisou não apenas a performance dos alunos, mas também a atuação do professor/pesquisador na proposta desenvolvida.

\footnotetext{
${ }^{1}$ researcher-is-researched

${ }^{2}$ researcher-and-researched
} 
A partir desta breve contextualização, ressalto que o objetivo deste artigo não é discutir os resultados e trazer dados da minha pesquisa de doutorado propriamente dita, mas sim fazer uma reflexão crítica sobre o estado da arte e discutir as implicações de se utilizar a autoetnografia como metodologia de pesquisa em contextos escolares, partindo da minha experiência e da minha perspectiva como autoetnógrafo no estudo desenvolvido. Desta forma, buscarei trazer possíveis contribuições para a fundamentação teórica sobre este tema ainda pouco discutido nas pesquisas em LA no Brasil.

$\mathrm{Na}$ primeira seção, parto das teorizações existentes acerca da etnografia tradicional, cuja origem está na Antropologia, buscando fazer uma expansão do conceito e relacionando-o com suas possibilidades de utilização em pesquisas autoetnográficas, a partir da minha experiência enquanto praticante desta metodologia. Na seção seguinte, abordo as implicações do uso da autoetnografia em LA, sobretudo em contextos escolares e em pesquisas na área de ensino e aprendizagem de línguas. Problematizo, então, a questão das identidades do professor/pesquisador envolvido nesta modalidade de pesquisa e as narrativas que emergem a partir dos conflitos observados em sua prática. Na seção subsequente, lançando mão dos escritos de Bakhtin (1997 [1979]), nos quais o autor discorre a respeito dos conceitos de autoria e autoridade na escrita da biografia e da autobiografia, busco fazer conexões, problematizando algumas questões no que tange à etnografia e à autoetnografia, principalmente no que se refere às figuras do herói e do narrador, no termos de Bakhtin, bem como acerca dos conflitos de identidade que surgem da relação entre o sujeito pesquisador (observador) e o sujeito pesquisado (observado). Finalmente, discuto a validação do conhecimento e a legitimidade da pesquisa autoetnográfica, a qual ainda é muito criticada, sobretudo a partir da visão tradicional da ciência positivista, e concluo problematizando a questão da inevitabilidade da subjetividade do pesquisador seja qual for a modalidade de pesquisa empregada.

\section{A etnografia e a autoetnografia: o que a Antropologia tem a nos dizer?}

A fim de embasar minhas teorizações acerca da autoetnografia, tomo como ponto de partida a etnografia tradicional, isto é, aquela cuja 
definição foi estabelecida na Antropologia, para, em seguida, propor uma expansão do conceito.

Segundo Rocha e Eckert (2008, p. 2), a observação direta, através da pesquisa etnográfica, engloba a necessidade de estudarmos o outro, numa relação de alteridade, para compreendê-lo mais profundamente. Portanto, a observação conduziria à possibilidade de olhar o outro para compreendê-lo e, da mesma forma, para buscarmos nos compreender melhor. A fim de alcançar tal objetivo, o processo de escrita do diário de campo representa uma tarefa importante para a sistematização das situações observadas, de maneira que o pesquisador possa se apropriar de sua própria experiência em campo para construir sentido das vivências observadas. Consequentemente, o diário de campo não consiste somente em um instrumento para registrar as situações observadas. Para Rocha e Eckert (2008, p. 15), o diário pode ser um espaço para o pesquisador avaliar sua conduta, seus erros e seus acertos, a fim de planejar e fazer redirecionamentos em suas ações futuras, numa vigilância epistemológica contínua. Conforme aponta Clifford (1998, p. 39), o etnógrafo leva consigo os diversos tipos de textos gerados para posterior interpretação, inclusive suas memórias e outros eventos retirados de seu contexto para serem reinterpretados futuramente.

Para Versiani (2002), com base nos estudos antropológicos de Clifford (1998), a intersubjetividade que está presente na relação entre o etnógrafo e o etnografado é um fator fundamental neste tipo de pesquisa. De certo modo, a intersubjetividade poderia ser interpretada como a habilidade de compartilhar a experiência vivenciada pelo outro. Desta maneira, poderia ser entendida como uma forma de imersão observadora e analítica na experiência vivida, considerando-se os aspectos verbais e comportamentais dos sujeitos envolvidos em uma determinada situação. Por outro lado, tal visão do conjunto observado, um tanto limitada, pode, muitas vezes, representar somente uma visão parcial, já que a intersubjetividade reuniria também a compreensão do que acontece na mente do outro. Assim, a perspectiva intersubjetiva apontaria os processos mais conscientes do não verbal, na tentativa de não cair em um entendimento neutro e raso da experiência subjetiva do outro.

$\mathrm{Na}$ minha visão, entendo que Clifford (1998) sinaliza para uma questão importante sobre a etnografia que é a necessidade de o etnógrafo evitar uma descrição reducionista e abstrata do outro. Para ele, é necessário que o etnógrafo adote uma postura a qual deve formar imagens complexas 
e concretas dos observados, a fim de levar em conta as relações de poder que estão imbricadas nesta relação entre o pesquisador e o pesquisado. No entanto, ele enfatiza que nenhum método de pesquisa científico pode garantir a verossimilhança das imagens construídas. Além disso, o autor advoga que a observação participante precisa ser entendida de forma hermenêutica, como uma "dialética entre experiência e interpretação" (CLIFFORD, 1998, p. 32), ou seja, transformar experiências significativas em interpretação. Segundo o autor, então, a experiência assumiria um status de autoridade etnográfica por meio da garantia "do eu estava lá" (CLIFFORD, 1998, p. 33). Ao relatarem sua experiência etnográfica em uma escola da rede pública de Porto Alegre, Garcez e Schulz (2015, p. 4) corroboram esta premissa, afirmando: "estivemos lá, vivemos as cenas, acompanhando as pessoas de carne e osso fazendo o dia a dia dessa escola". Entretanto, Clifford tece algumas críticas à visão que se tinha do etnógrafo, estabelecida na primeira metade do século XX, segundo a qual este era visto com um status de autoridade, mesmo usando como base para sua escrita relatos de uma experiência de caráter subjetivo, singular e pessoal. Eriksson (2010, p. 93) afirma que há um enorme ceticismo em relação a métodos de investigação científica envolvendo o pesquisador enquanto indivíduo participante. Para ele, na etnografia, a subjetividade do eu (pesquisador), enquanto instrumento de pesquisa, é vista como perigosa. Inclusive, ressalta que há uma tendência para que se busque a redução ou mesmo a eliminação do papel do pesquisador/observador.

Tais apontamentos sugerem a necessidade de uma descrição mais densa (GEERTZ, 2008 [1973]) das situações observadas em campo, de modo que se evite um entendimento superficial do outro. $O$ conceito de descrição densa (thick description), problematizado pelo teórico, refere-se a um aspecto fundamental da etnografia, por meio do qual a interpretação do analista precisa considerar o fato de que grande parte do que é preciso para compreendermos um contexto ou um comportamento, seja qual for a situação observada, "está insinuado como informação de fundo antes da coisa em si mesma ser examinada" (GEERTZ, 2008 [1973], p. 7). Ou seja, uma descrição densa deve considerar a "multiplicidade de estruturas conceptuais complexas" (GEERTZ, 2008 [1973], p.7), as quais se encontram "sobrepostas ou amarradas umas às outras, que são simultaneamente estranhas, irregulares e inexplícitas" (GEERTZ, 2008 [1973], p. 7). Geertz ressalta que o etnógrafo precisa estar situado em sua investigação, alegando que o ato de situar-se na pesquisa etnográfica, 
enquanto uma forma de experiência particular, só pode ser bem-sucedido parcialmente, visto que a busca pela base na qual se imagina estar situado transcorre de maneira incessante no fazer científico.

Considerando o exposto por Geertz, observo, a partir da minha experiência no estudo que desenvolvi, que a pesquisa autoetnográfica facilita o ato de situar-se, uma vez que a situação e o campo nos quais se está imerso são bastante familiares para a figura do pesquisador/pesquisado. Isto se dá devido ao caráter controverso em que a identidade do sujeito pesquisador coexiste de maneira simultânea e, frequentemente, até se confunde com a identidade do sujeito pesquisado. Assim, o uso da autoetnografia consiste em estabelecer um diálogo constante consigo mesmo. Logo, apesar de não parecermos estranhos a nós mesmos, por diversos momentos este diálogo pode ser conflituoso, já que nem sempre nossas práticas são reflexos do que teorizamos e vice-versa. Na pesquisa autoetnográfica, remete-se à importância de adotarmos uma perspectiva dialógica e polifônica da investigação, em que há um estreitamento da distância entre o pesquisador/observador e o pesquisado/observado, e que se dá pela manifestação simultânea das vozes de ambos, pelo fato de se tratarem do mesmo sujeito. De acordo com Eriksson (2010, p. 97),

Ao fazer pesquisa em meu próprio quintal cultural, já sou considerado um insider, aceito como uma parte natural do sistema. Tenho um bom ângulo de visão e minha presença não incomoda o sistema social de nenhuma maneira anormal. Sou um verdadeiro nativo. [...] Facilmente me misturo. Um pesquisador vindo de fora poderia ser um observador mais óbvio e intruso, influenciando as ações das pessoas em maior grau. ${ }^{3}$

No entanto, o autor supracitado também questiona a relevância desta aproximação do pesquisador em relação ao seu objeto de pesquisa, indagando se não seria mais desafiador enxergar a realidade de determinado contexto a partir de uma perspectiva de dentro (insider) e,

\footnotetext{
${ }^{3}$ When doing research in my own cultural backyard, I am already an insider, an accepted and natural part of the social system. I have a good viewpoint and my presence doesn't seem to disturb the system in any abnormal way. I am a true native. [...] I easily blend in. A researcher coming from afar might be more obvious as an intruding observer, influencing peoples' actions to a larger extent.
} 
portanto, parcial, do que a partir de uma perspectiva de fora (outsider), como se o observador fosse suspenso por um guindaste e tivesse a visão de uma lente panorâmica do todo. Considerando o exposto, trago à tona o pensamento de Arruda (2012), o qual propõe alguns questionamentos importantes acerca do papel interpretativo do etnógrafo. Para o autor:

A prática etnográfica tradicional favorece o distanciamento em relação ao objeto e não a proximidade, com vista a uma leitura rigorosa, imune aos interesses individuais do observador. Por outro lado, o pressuposto da autenticidade não pode ser encarado levianamente, constituindo um dos desafios mais complexos da etnografia: o que é a autenticidade? Pode esta ser apreendida pela etnografia? O que está dentro vê melhor a 'sua' realidade social? E conseguirá traduzi-la de forma inteligivel para alguém que está de fora? (ARRUDA, 2012, p. 10, aspas do autor).

Arruda salienta que o fato de o observador estar integrado ao contexto investigado não garante que este tenha um melhor entendimento de sua realidade social, ou ainda que o tenha, não é certeza que possa traduzir sua experiência para quem está do lado de fora.

$\mathrm{Na}$ perspectiva da etnografia tradicional, Versiani (2002) defende que a função do etnógrafo, a qual seria a de representar o outro, ou seja, "falar sobre o Outro, ou pelo Outro", deveria ser, no entanto, a função de "falar com o Outro" (VERSIANI, 2002, p. 67, itálico da autora), por meio de um diálogo contínuo em que as vozes de ambos, pesquisador e pesquisado, pudessem se manifestar através de uma escrita dialógica e polifônica. Observo, em relação à autoetnografia, que esta polifonia se dá de maneira constante e intercambiante, uma vez que o eu pesquisador assume a identidade do $e u$ pesquisado, e vice-versa, num constante diálogo do (auto)etnógrafo consigo mesmo, resultando numa "dupla consciência" (DU BOIS, 1996, apud ARRUDA, 2012, p. 10) ${ }^{4}$. Este paradoxo experimentado pelo autoetnógrafo é corroborado por Doloriert e Sambrook (2009, p. 30), as quais ressaltam que, nesta relação entre o pesquisador e o pesquisado, o auto se torna também o etno, pois o observador é parte integrante do grupo observado. O conceito do falar com o outro, discutido

${ }^{4}$ DU BOIS, William E. B. The Souls of Black Folk. London: Penguin Classics, 1996. 
por Menezes de Souza (2011a), com base no pensamento freiriano, aborda o processo de conscientização acerca da complexidade em assumir a diferença entre "estar no mundo" (perspectiva ingênua) para "estar com o mundo" (percepção da complexidade), por meio da percepção crítica de que nunca estamos sozinhos (MENEZES DE SOUZA, 2011a, p. 130-131). Para o teórico, a consciência social e crítica nos mostra que, a partir da coletividade, a percepção de si mesmo como um eu emerge da consciência de um não-eu, o qual se conecta ao eu individualizado. Ao problematizar o conceito da dupla consciência discutido por Du Bois, Arruda (2012, p. 11) advoga que não se trata apenas da "dupla consciência de quem absorve duas realidades identitárias e culturais, mas do duplo papel do sociólogo enquanto sujeito e objeto" que constrói sentidos através da autorreflexão.

\section{E professor, pode?}

No cenário acadêmico da atualidade, observa-se a ocorrência de diversos tipos de etnografias não tradicionais ou não canônicas (FORTIN, 2009; ELLIS; ADAMS; BOCHNER, 2011), tais como a autoetnografia e a netnografia. Green e Bloome (2008) discutem as transformações que a etnografia tem sofrido ao longo das últimas décadas e, conforme apontam, não é de hoje que a discussão sobre o que conta como etnografia tem ocorrido.

De acordo com Arruda (2012, p. 10), a autoetnografia tem sua origem na Antropologia, porém vem sendo muito empregada na Sociologia, sobretudo em estudos feministas e pós-coloniais. No entanto, para Ono (2017, p. 145), a autoetnografia ainda pode ser considerada uma abordagem metodológica recente no Brasil, principalmente em relação às pesquisas na área de formação de professores e de ensino e aprendizagem de línguas. Talvez esta lacuna de teorizações se deva ao fato de que alguns antropólogos ainda critiquem a utilização da etnografia e, consequentemente, também da autoetnografia, em outras áreas para além da Antropologia. Segundo Garcez e Schulz (2015, p. 21), existem pesquisadores em Antropologia no Brasil que se posicionam contrários ao uso da [auto]etnografia em outras áreas, reclamando para si a exclusividade do método e alertando para os riscos da popularização do seu uso em outras esferas, sob o argumento de que há a falta de critérios e de uma formação antropológica apropriada por parte de pesquisadores de diferentes searas. 
Além disso, enquanto metodologia, a autoetnografia ainda é alvo de outras críticas, sobretudo a partir de perspectivas mais ortodoxas de base positivista (DOLORIERT; SAMBROOK, 2009). Contrapondo-se às opiniões dos antropólogos, Starr (2010, p. 2) defende que a autoetnografia é uma ferramenta valiosa para analisarmos os diversos contextos complexos da Educação, por meio da reflexão e da ação, como parte de um processo crítico de autoanálise e compreensão de discursos culturais e sociais.

Para Eriksson (2010, p. 93), acadêmicos que se utilizam da autoetnografia ainda enfrentam grandes desafios para que suas pesquisas sejam legitimadas como ciência e até mesmo para que seus trabalhos sejam aceitos para publicação. Devido a estes fatores, pesquisadores das áreas de LA e da Educação têm preferido denominar suas pesquisas como sendo do tipo etnográfica ou mesmo de cunho autoetnográfico. Apesar das críticas, a autoetnografia tem se mostrado uma alternativa metodológica às pesquisas científicas tradicionais de base positivista, por exemplo, em alguns estudos englobando as teorias de Letramentos e ensino de línguas e literaturas (cf. ONO, 2017; SILVA, 2011; SOARES, 2017).

Em relação à etnografia escolar, Garcez e Schulz (2015) advogam em favor de diversos aspectos positivos que a pesquisa desta natureza pode proporcionar. Assim, defendem que a etnografia "com base em descrição narrativa e transcrição de episódio interacional flagrado em sala de aula" contribui para o "entendimento adequado de ações situadas" (GARCEZ; SCHULTZ, 2015, p. 1). Além disso, argumentam que, por meio da interação em dado momento com os sujeitos participantes e também da aproximação a sua perspectiva, é possível estabelecer "conexões com estruturas sociais menos observáveis” (GARCEZ; SCHULTZ, 2015, p. 1), sendo, então, a etnografia fundamental para a compreensão do contexto, dos participantes e dos objetos de pesquisa.

Green e Bloome (2008, p. 1) argumentam que a etnografia precisa ser vista de forma situada, dentro e através de diferentes loci. Enfatizam, sobretudo, a importância de considerarmos seus usos nas mais diversas disciplinas, analisando as teorias e metodologias empregadas, seus pontos de vista e suas práticas de investigação. Neste entendimento, é importante observar que a etnografia não é vista como um conjunto de regras unitárias com um único critério para seu uso. Com relação aos critérios de sua utilização nas Ciências Sociais e em Educação, os autores nomeiam três abordagens possíveis, sendo elas "fazer etnografia, adotar uma perspectiva etnográfica e utilizar ferramentas etnográficas” (GREEN; BLOOME, 2008, 
p. 4) ${ }^{5}$. A primeira abordagem "envolve a teorização, conceituação, condução, interpretação, escrita e relatos associados a um amplo, aprofundado e longo estudo de um grupo cultural ou social, adotando os critérios da etnografia dentro de uma disciplina ou campo" (GREEN; BLOOME, 2008, p. 4) ${ }^{6}$. A segunda acepção promove um olhar mais focado e situado para investigar aspectos da vida diária ou práticas culturais de um grupo social, adotando o uso de teorias sobre cultura e investigação de práticas sociais advindas da Antropologia e da Sociologia. Já a terceira abordagem se refere ao uso de técnicas e metodologias de trabalho de campo, as quais podem ou não estar associadas a teorias de cultura e questões referentes à vida social do grupo.

Outrossim, tomando a Educação como um locus de investigação, Green e Bloome (2008, p. 2) distinguem duas perspectivas distintas em relação ao uso da etnografia, sendo elas: (1) etnografia- $d a$ - educação e (2) etnografia-em-educação ${ }^{7}$. A primeira perspectiva

envolve antropólogos e sociólogos que usam a Educação como local de estudo, trazendo teorizações, ferramentas de investigação e a história da sua própria disciplina para dentro do campo, a fim de construir e compreender o que conta como educação para um grupo local (GREEN; BLOOME, 2008, p.8) ${ }^{8}$.

Portanto, nesta abordagem, diferentes contextos educacionais são vistos como locais para o desenvolvimento das pesquisas em Ciências Sociais, a partir do uso da pesquisa etnográfica. Já em relação à segunda perspectiva, isto é, etnografia-em-educação, os estudos são embasados em conhecimentos advindos do campo da Educação, orientados por questões,

5 doing ethnography, adopting an ethnographic perspective, and using ethnographic tools.

${ }^{6}$ involves the framing, conceptualizing, conducting, interpreting, writing, and reporting associated with a broad, in-depth, and long-term study of a social or cultural group, meeting the criteria for doing ethnography as framed within a discipline or field.

7 ethnography-of-education and ethnography-in-education.

${ }^{8}$ involves anthropologists and sociologists using education as a place of study to which they bring theoretical frames, tools of inquiry, and a history from their field and discipline within the field to construct an understanding of what counts as education to a local group. 
objetivos, necessidades e preocupações educacionais, assim como são conduzidos pelos profissionais desta esfera, tais como professores e formadores de professores.

No que se refere ao processo de geração de dados, considerando minha experiência no estudo autoetnográfico desenvolvido durante minha pesquisa de doutorado, observo que se trata de um grande desafio. Isto ocorre devido ao fato de o professor/autoetnógrafo ser o responsável por elaborar o plano de aulas e o material para realizá-las, em seguida colocar em prática tudo o que foi planejado, saber lidar com as questões de sala de aula (tais como conquistar a atenção dos alunos, organizar os espaços e recursos didáticos, administrar conflitos, indisciplina, etc.) e, além disso, gerar os dados (caso não tenha um assistente para isso, como era o meu caso). Muitas vezes é preciso utilizar diversos instrumentos diferentes (anotações no diário de campo, fotografias, gravações de áudio ou vídeo, etc.) e, em alguns casos, mais de um ao mesmo tempo.

No caso da autoetnografia escolar, a figura do professor/autoetnógrafo precisa se valer de muitos artifícios para dar conta de ministrar sua aula e, ao mesmo tempo, observar de forma participante os eventos ocorridos durante sua própria prática pedagógica. Neste caso, além das anotações em seu diário de campo, a utilização de gravações de áudio e/ou vídeo é fundamental para que possa revisitar suas práticas e, posteriormente, construir sentido das situações vivenciadas.

Considerando que a pesquisa autoetnográfica possui um caráter de maior exposição do pesquisador (DOLORIERT; SAMBROOK, 2009), uma vez que há a impossibilidade de seu anonimato, ela desnuda os medos, inseguranças, incertezas e deflagra mais diretamente a relação, nem sempre harmoniosa, em que o pesquisador também se torna o pesquisado, podendo revelar até mesmo experiências traumáticas e de foro íntimo. De certo modo, isto consiste em assumir o caráter indissociável entre o indivíduo que conduz a investigação e o próprio processo de produção da pesquisa (FORTIN, 2009). Para tanto, é importante considerar a reflexão sobre as questões relacionadas às identidades do $e u$ (pesquisador/observador) e do eu (pesquisado/observado). Tais identidades emergem no contexto da pesquisa e torna-se necessário problematizar a subjetividade, a alteridade e a interdependência entre estes dois eus.

Conforme Doloriert e Sambrook (2009, p. 35), talvez um dos maiores desafios nesta modalidade de pesquisa seja ponderar quais momentos críticos da pesquisa devem ser revelados, ou ainda quais 
histórias e momentos pessoais são relevantes para a narrativa autoetnográfica. Desta forma, é necessário estabelecer um equilíbrio entre o quanto do eu e o quanto do(s) outro(s) deve ser incluído ou excluído da narrativa.

\section{Contribuições de Bakhtin para a discussão sobre autoetnografia}

Em suas teorizações acerca do gênero autobiografia, Bakhtin (1997 [1979], p. 165) discute esta posição intercambiável do autor consigo mesmo, denominada pelo teórico como uma relação eu-para-mim, a qual eventualmente proporciona esta coincidência entre o herói e o autor da narrativa. No entanto, esta coincidência promove uma contradição, de acordo com a visão bakhtiniana, pois, já que é parte do todo artístico da narrativa, o autor não poderia coincidir com o herói que também a integra. Consequentemente, esta situação inusitada poderia gerar conflitos de identidade e indagações do tipo: "como me represento a mim mesmo?" Ou ainda "quem sou eu?" (BAKHTIN, 1997 [1979], p. 165). De acordo com Bakhtin, o valor biográfico é o que menos transcende à autoconsciência, uma vez que o autor "situa-se muito próximo de seu herói: eles parecem ser intercambiáveis nos lugares que ocupam respectivamente e é por esta razão que é possível a coincidência de pessoas entre o herói e o autor" (BAKHTIN, 1997 [1979], p. 165). A fim de problematizar melhor esta questão, o teórico argumenta que este valor é o que organiza a narrativa da vida do outro, porém, ao mesmo tempo, serve para organizar o que eu mesmo tenha vivido, ou seja, a narrativa que conta minha própria vida e que molda o discurso autoconsciente e a visão que tenho sobre mim.

Considerando minhas percepções a partir da experiência enquanto autoetnógrafo, percebo que o intercâmbio de vozes entre pesquisador e pesquisado se dá de maneira tão contínua e intensa que pode provocar uma crise de cunho existencial. De acordo com Eriksson (2010, p. 94), trata-se da experiência de analisar e refletir metodológica e conscientemente sobre os diferentes papéis habitados pelo pesquisador no trabalho autoetnográfico. Para Sartre (1987, p. 2), sob a ótica do existencialismo, a subjetividade tratada no âmbito da verdade não é algo estritamente individual, visto que, a partir do encontro com o outro, não somente descubro a mim mesmo, mas o outro também é revelado para mim. 
Do ponto de vista da Sociologia, consoante o pensamento do teórico Stuart Hall, "o sujeito ainda tem um núcleo ou essência interior que é o 'eu real', no entanto este é formado e modificado num diálogo contínuo com os mundos culturais 'exteriores' e as identidades que esses mundos oferecem" (HALL, 1998, p. 11, aspas do autor). Buscando encontrar soluções para tais conflitos que povoam a consciência do autoetnógrafo, num diálogo intersubjetivo contínuo consigo mesmo, recorro ao pensamento de Gadamer, o qual afirma que o caráter dialogal da linguagem "ultrapassa o ponto de partida da subjetividade do sujeito" (GADAMER, 2002, p. 387). Esta condição intercambiante das vozes, as quais se manifestam no diálogo entre o etnógrafo e o etnografado, consolida a relação de alteridade entre ambos. No que diz respeito ao caráter dialogal da linguagem, Gadamer (2002, p. 387) advoga que:

A experiência dialogal aqui produzida não se limita à esfera das razões de uma ou outra parte, cujo intercâmbio e coincidência podem definir o sentido de todo o debate. Há algo mais, como mostram as experiências descritas; um potencial de alteridade, por assim dizer, que está além de todo consenso comum.

Com o intuito de estabelecer conexões com o exposto por Gadamer, recorro a Bourdieu (1996, p. 5), o qual, ao discutir os conflitos de legitimidade e da autoridade das vozes que se manifestam entre os interlocutores de produções linguísticas, afirma que:

A estrutura da relação de produção linguística depende da relação de força simbólica entre os dois locutores, isto é, da importância de seu capital de autoridade (que não é redutível ao capital propriamente linguístico): a competência é também portanto capacidade de se fazer escutar.

Considerando as asserções de Gadamer e Bourdieu, proponho uma discussão que trata da força simbólica destas duas identidades (sujeito observador e sujeito observado) envolvidas na pesquisa autoetnográfica, no que se refere não apenas, mas também ao processo de análise e interpretação dos dados neste tipo de estudo. No que tange à legitimização das vozes do pesquisador e do pesquisado, percebo, através da minha própria experiência como autoetnógrafo, um verdadeiro cabo de guerra entre estes dois sujeitos, bem como as relações de poder envolvidas, em 
que frequentemente a voz do pesquisador, através de sua força simbólica, corre o risco de se tornar manipuladora, caso ele não esteja em uma constante vigilância epistemológica acerca da subjetividade de sua análise. A partir do pensamento de Bakhtin (1997[1979]), exposto a seguir, sugiro uma forma de refletirmos sobre as identidades do pesquisador/pesquisado na pesquisa autoetnográfica, fazendo uma analogia com os conflitos gerados na relação do biógrafo com o biografado:

O autor da biografia é o outro possível, cujo domínio sobre mim na vida admito com a maior boa vontade, que se encontra ao meu lado quando me olho no espelho, quando sonho com a glória, quando reconstruo uma vida exterior para mim; é o outro possivel que penetrou em minha consciência e que com freqüência me governa a conduta, o juizo de valor e que, na visão que tenho de mim, vem colocar-se ao lado de meu eu-paramim; é o outro instalado em minha consciência, com quem minha vida exterior pode conservar uma suficiente maleabilidade (a vida interior - sobre a qual o domínio do outro exerce sua tensão tornou-se, claro, impossível, e é aí que é travado o combate contra o outro, para libertar o meu eu-para-mim em toda a sua pureza), é o outro que também poderia tornar-se meu duplo-usurpador se eu deixasse, se não o vencesse; é o outro com quem, não obstante, posso viver, com toda espontaneidadeingenuidade, uma vida movimentada e feliz (é verdade que esse outro também pode entregar-me ao poder da fatalidade - o domínio sempre pode tornar-se fatal) (BAKHTIN,1997 [1979], p. 166-167, negrito e parênteses do autor).

A meu ver, a relação de autoria/autoridade que se estabelece entre o autor e o biografado, de acordo com o exposto por Bakhtin, pode ser ressignificada a partir da visão que tenho enquanto etnógrafo/etnografado. $\mathrm{Na}(\mathrm{s})$ minha(s) perspectiva(s) - uma vez que a situação controversa na qual eu, enquanto autor/analista/intérprete das minhas próprias práticas, me coloco diante de um espelho em que do outro lado vejo minha própria figura, porém já não mais como pesquisador, mas sim como professor/etnografado e vice e versa - os conflitos da ordem dominador/dominado operam de ambos os lados, de certa modo consentidos, porém não naturalizados, e evocam uma dupla identidade, isto é, o eu-para-mim e o eu-para-o-outro (usando este neologismo criado a 
partir do conceito original de Bakhtin). Desta forma, ao incorporar a persona de pesquisador, tenho para mim duas visões: o eu-para-mim (minha perspectiva pesquisador/etnógrafo, enquanto observador participante) e o eu-para-o-outro (perspectiva do etnografado que vê o outro como seu analista/intérprete). Entretanto, ao vestir a máscara do pesquisado, o eu-para-mim assume a perspectiva do professor, enquanto sujeito realizador das práticas em sala de aula, e o eu-para-o-outro transforma-se no sujeito etnografado/objeto da investigação. A partir daí, instaura-se o combate travado com o outro, em que o meu eu-para-mim qual for o lado do espelho que eu me posicione, seja do pesquisador, seja do pesquisado - tenta tornar-se meu duplo usurpador, numa tensão contínua em que o domínio alcançado por qualquer um dos lados pode ser fatal. Assim, a suposta autoridade que o pesquisador teria sobre o pesquisado influencia a construção da própria narrativa de forma consentida pelo pesquisado, pois "a posição de valor do outro tem autoridade sobre mim, ele pode conduzir a narrativa da minha própria vida e estarei interiormente de pleno acordo com ele" (BAKHTIN, 1997 [1979], p. 167).

Sendo assim, é importante considerarmos a complexidade envolvendo a questão da "imparcialidade" e da vaidade do pesquisador em relação ao seu objeto de pesquisa, pois "na medida em que ele é efetivamente validado por mim e seus valores são determinantes para a minha vida [...] é que ele pode tornar-se o autor da minha vida, um autor que me é interiormente inteligível e tem autoridade sobre mim" (BAKHTIN, 1997 [1979], p. 168, itálico do autor).

Deste modo, segundo Arruda (2012), a dupla identidade do autoetnógrafo, enquanto sujeito e objeto, "não lhe fornece o direito de achar-se superior aos seus objetos de estudo nem de interpretá-los consoante os seus interesses" (ARRUDA, 2012, p. 11). Além disso, conforme Eriksson (2010, p. 94), é preciso estar atento para o risco de a pesquisa se tornar demasiadamente narcisista e autoindulgente. A partir da visão do autor, entendo que fazer autoetnografia não é assumir que o $e u$ pesquisador seja mais importante que o eu pesquisado. Trata-se de observar de que maneira o estudo do meu eu (individual), isto é, do pesquisador/pesquisado, pode contribuir para a investigação de questões importantes para um eu (coletivo), ou seja, professores e pesquisadores de outros contextos que possam tirar proveito dos resultados da minha 
experiência pessoal e, assim, ressignificá-la localmente para seus próprios contextos de atuação.

Gadamer (2002), ao discutir o conceito hegeliano da dialética do reconhecimento, propõe o conhecimento de si mesmo por meio da alteridade. $\mathrm{O}$ autor ainda indaga sobre a intermediação da alteridade do outro e da maneira como esta poderia ser vista: como uma ponte ou como uma barreira? Em linhas gerais, a primeira opção resultaria em uma ponte que serviria para a construção de sentidos através da comunicação de um com o outro "sobre o rio da alteridade" (GADAMER, 2002, p. 388). Já a segunda se tornaria uma barreira para a comunicação de forma plena por meio de uma autoentrega de ambos.

Simpatizando-me com a metáfora de Gadamer, o posicionamento que adoto debate a autoetnografia através de uma perspectiva dialética, vista como uma ponte para a alteridade, pois este posicionamento não reprime, mas sim enaltece o caráter contraditório, conflitante e em permanente transformação destas duas identidades concomitantes, pesquisador e pesquisado, que emergem de modo instável e dinâmico, num constante movimento intercambiante de um lado para o outro da ponte.

\section{A validação do conhecimento e a legitimidade da pesquisa autoetnográfica}

Starr (2010, p. 3) argumenta que a experiência pessoal do pesquisador tem o potencial de promover um novo entendimento da situação ou cultura investigada, e que este entendimento é revelado através de uma visão holística que engloba a pesquisa, a escrita, a análise e a disseminação do conhecimento como se fosse uma ponte entre o aspecto pessoal e os aspectos culturais, políticos e sociais. No entanto, Konder (1981) discorre sobre o caráter instável, dinâmico e provisório da visão da totalidade numa situação dada. Para ele:

A visão do conjunto - ressalve-se - é sempre provisória e nunca pode pretender esgotar a realidade a que ele se refere. A realidade é sempre mais rica do que o conhecimento que a gente tem dela. Há sempre algo que escapa às nossas sínteses; isso, porém, não nos dispensa do esforço de elaborar sínteses, se quisermos entender melhor a nossa realidade. A síntese é a visão 
A autoetnografia em pesquisas em Linguística Aplicada...

de conjunto que permite ao homem descobrir a estrutura significativa da realidade com que se defronta, numa situação dada. E é essa estrutura significativa - que a visão de conjunto proporciona - que é chamada de totalidade (KONDER, 1981, p. 37 , negrito do autor).

Portanto, a noção de que o indivíduo pesquisador/pesquisado possa alcançar uma visão do conjunto da realidade ou uma exotopia (BAKHTIN, 1997 [1979]), uma vez que se encontra imerso no contexto observado, incorporando ambas as figuras de etnógrafo e de etnografado, isto é, dentro e fora ao mesmo tempo, limita-se a uma visão provisória e inacabada. Com base em Konder (1981), defendo que, no locus em que se inscreve o estudo autoetnográfico com ênfase na vida escolar, o ethos do pesquisador não dá conta de alcançar a pretensa totalização do processo de análise e interpretação dos dados de forma definitiva e acabada, pois a dupla identidade assumida por ele, ou seja, pesquisador e pesquisado, encontra-se em construção, sempre em busca da totalidade do processo por meio das sínteses das análises das experiências vivenciadas no ambiente escolar. Além disso, é necessário salientar que, em se tratando da pesquisa autoetnográfica escolar, há ainda outro grupo de observados que são os alunos. Estes constituiriam, então, uma terceira parte dos envolvidos. Assim, no que diz respeito à soma das partes que constituem a totalidade da pesquisa autoetnográfica escolar, temos (1) os alunos/sujeitos etnografados participantes da pesquisa; (2) o sujeito professor/(auto)etnografado; (3) o sujeito pesquisador/(auto)etnógrafo.

Em vista disso, compartilho o pensamento de Konder (1981, p. 39, itálico do autor), o qual afirma que "a totalidade é apenas um momento de um processo de totalização" que está sempre em construção e nunca encontra uma forma definitiva e acabada, uma vez que seu caráter dialético instaura uma "maneira de pensar elaborada em função da necessidade de reconhecermos a constante emergência do novo na realidade humana" (KONDER, 1981, p. 39). Por este motivo, as situações analisadas precisam ser constantemente revisitadas e revistas, para que, sob as diversas perspectivas envolvidas na visão do conjunto da pesquisa, ou seja, pesquisador, professor e alunos, possamos experimentar a emergência do novo, de maneira crítica e autocrítica, numa realidade em constante mudança. Considerando que a análise dos dados nada mais é que uma interpretação das situações vivenciadas pelo autoetnógrafo, é necessário 
estarmos atentos aos questionamentos sugeridos por Gadamer (2002, p. 391): "Existirá uma realidade que permita buscar com segurança o conhecimento do universal, da lei da regra, e que encontre aí sua realização? Não é a própria realidade o resultado de uma interpretação?"

A partir desta premissa, a interpretação das situações observadas em campo constitui de fato apenas uma realidade provisória daquele contexto analisado, uma vez que "a interpretação é o que oferece a mediação nunca acabada e pronta entre homem e mundo, e nesse sentido a única imediatez verdadeira e o único dado real é o fato de compreendermos algo como algo" (GADAMER, 2002, p. 391). Além disso, o referido teórico argumenta que o conhecimento "não pode evitar a consequência hermenêutica de que a realidade 'dada' é inseparável da interpretação" (GADAMER, 2002, p. 391, aspas do autor) e também que "um texto não é um objeto dado, mas uma fase na realização de um processo de entendimento" (GADAMER, 2002, p. 391). Assim sendo, com base no pensamento nietzschiano, ele recorre ao questionamento: "Será que essa ideia significa que interpretar é impor um sentido e não encontrar um sentido?" (GADAMER, 2002, p. 392, itálico do autor).

Por outro lado, não podemos deixar que tendências positivistas e empiricistas invalidem ou deslegitimem o caráter científico da autoetnografia, sob o pretexto da busca pela "verdade imparcial". De acordo com Junior (1983, p. 18), a filosofia positivista, consoante o pensamento de Comte, busca a unidade na explicação dos fenômenos universais, sem considerar concepções abstratas e metafísicas, utilizando, exclusivamente, o método empírico ou verificação experimental. Os fundamentos do positivismo, segundo o autor, adotam uma metodologia de trabalho de natureza indutiva e baseada na observação dos fatos "adivinhando-lhes por indução as leis da coexistência e da sucessão, e deduzindo dessas leis, por via da consequência e correlação, fatos novos que escaparam da observação direta, mas que a experiência verificou" (JUNIOR, 1983, p. 18). Assim, Junior destaca que a filosofia positivista se nega a indagar a respeito da essência e da causalidade dos fenômenos, priorizando, então, a procura das relações constantes e das leis observáveis pela experiência dos sentidos exteriores. Ademais, tem como premissa investigar os fenômenos "pelo uso combinado do raciocínio e da observação, as suas leis efetivas, isto é, as suas relações invariáveis de sucessão e semelhança” (JUNIOR, 1983, p. 19). Portanto, nas pesquisas de base positivista, nas quais definitivamente a autoetnografia não se inscreve, 
há um enaltecimento da construção do conhecimento de forma a promover sua validade, confiabilidade e generalização.

Por seu caráter pós-moderno, a autoetnografia reconhece a impossibilidade de criar narrativas universais. Trata-se de assumir a impossibilidade da neutralidade, da objetividade e da impessoalidade da pesquisa científica, assim como reconhecer que a construção do conhecimento pode acomodar a subjetividade e a influência do pesquisador, em vez de tentar esconder ou fingir que estas questões não existem (ELLIS; ADAMS; BOCHNER, 2011). Para Starr (2010, p. 2), a crença de que a pesquisa acadêmica precisa se articular de forma a promover evidências - e sua subsequente aplicação genuína - não atende às demandas pragmáticas da pesquisa em Educação. Segundo ela, o valor prático da autoetnografia se constrói através da experiência pessoal, pois a autoetnografia propõe que "o avanço do conhecimento vem da habilidade do pesquisador em relacionar os microdetalhes de um estudo com as macroimplicações de ideias e conceitos" (STARR, 2010, p. 2). Desta forma, para a autora, um estudo conduzido a partir desta metodologia fornece análises e evidências relevantes dentro de um contexto que extrapola a simples reconstrução da prática vivida e promove profundas transformações pessoais para uma mudança de paradigma, tanto para quem está engajado na pesquisa, quanto para quem lê seus relatos. Portanto, a questão da identidade se torna central neste processo. Starr ainda ressalta que nós, pesquisadores, "precisamos nos mover para além das práticas de pesquisas hegemônicas fundamentadas em epistemologias ocidentais à custa da negligência de conhecimentos locais" (STARR, 2010, p. 2). Para ela, a pesquisa autoetnográfica, de caráter qualitativo e pós-moderno, consiste em uma metodologia em que o estudo detalhado da realidade observada é essencial para a autenticidade do método. No entanto, essa riqueza de detalhes nem sempre aparece de forma linear, estruturada ou mesmo lógica, mas ainda assim é fundamental para a compreensão das práticas realizadas.

\section{Considerações finais}

Ressalto a importância de reiterar que a pesquisa autoetnográfica possui o caráter de uma autoanálise em seus mais diversos aspectos. Dentre alguns fatores, esta metodologia nos auxilia a questionar nossas próprias 
práticas, nossas vaidades, bem como nossas identidades. Ao mesmo tempo, nos fornece subsídios para que possamos promover mudanças a partir da reflexão crítica acerca da nossa atuação enquanto professorespesquisadores. Apesar da condição de vulnerabilidade e desnudamento (DOLORIERT; SAMBROOK, 2009; ELLIS; BOCHNER, 2000; ERIKSSON, 2010) do pesquisador/pesquisado, o qual é altamente exposto a críticas e autocríticas nesta modalidade de pesquisa, na qual se avalia não apenas seus acertos, mas também suas falhas, é preciso considerar o fator da empatia por parte do leitor de seus escritos. Muitas vezes, este também está situado na mesma posição, seja de professor, seja de pesquisador, ou ambos, e, desta forma, compreende, se solidariza e até mesmo se identifica com os desafios e as dificuldades de como é "estar lá" na sala de aula.

Salvaguardando-se todas as especificidades da etnografia/autoetnografia no que tange às pesquisas em Antropologia, as críticas por parte de alguns antropólogos direcionadas aos pesquisadores em LA ilustram, de forma significativa, o antagonismo presente no ambiente acadêmico, indicando que a construção do conhecimento, infelizmente, ainda é vista por alguns como uma série de elementos e teorias dissociadas e subdivididas em categorias ou "caixinhas", orientadas por vertentes de pensamento isoladas, guiadas por seus mentores e difundidas por seus respectivos seguidores. Segundo Varghese e Johnston (2007), seria mais interessante substituirmos o pensamento antagônico adotado por alguns pesquisadores, que se dedicam a provar que determinada perspectiva está errada e que sua visão seria a mais correta, por um posicionamento mais dialógico e que considerasse todas as complexidades envolvidas nos contextos de pesquisa. De fato, ainda que adotemos todo o rigor de uma pesquisa científica, a auto-observação evidencia a necessidade de assumirmos o caráter subjetivo das nossas interpretações e conclusões, as quais, para Varghese e Johnston (2007, p. 13), serão sempre "coloridas e filtradas pela nossa posição enquanto sujeitos e, portanto, seria ingênuo clamar pela objetividade nas nossas interpretações". Além disso, a pesquisa autoetnográfica pode trazer contribuições em relação à maneira como interpretarmos e reinterpretarmos nossas experiências em campo, por meio da observação de práticas situadas localmente e da negociação de sentidos entre nós e nossos alunos. A partir deste processo consciente de "ler-se lendo" (MENEZES DE SOUZA, 2011b, p. 296), é importante observar os questionamentos sugeridos pelo teórico: "Por que entendi assim? Por que acho isso? De onde vieram as 
minhas ideias, minhas interpretações?” (MENEZES DE SOUZA, 2011b, p. 296). A partir destes questionamentos e do processo de auto-observação, é possível nos situarmos dentro de nossa própria história e cultura, bem como ampliarmos o entendimento acerca de nossas narrativas e de nossa(s) identidade(s) em relação ao outro.

Além disso, apesar de ser alvo de diversas críticas, conforme apontado ao longo deste artigo, outro ponto positivo em relação à autoetnografia se refere às contribuições que este tipo de pesquisa pode promover no campo investigado. Diferentemente da etnografia tradicional, em que muitos pesquisadores são acusados de ir a campo, sobretudo em escolas pobres da periferia, realizar suas pesquisas por meio da observação de tais contextos, invadindo a privacidade dos sujeitos, e, ao finalizá-las, ir embora sem dar nada em troca, a autoetnografia tem o potencial de promover o aprimoramento das práticas realizadas nos próprios contextos observados, através de uma autoanálise da atuação do pesquisador/pesquisado e dos alunos das salas de aulas investigadas.

\section{Referências}

ANDRÉ, Marli E. D. A. Etnografia da prática escolar. Campinas: Papirus, 1995.

ARRUDA, José P. Tese e Antítese: a autoetnografia como proposta metodológica. In: VII CONGRESSO PORTUGUÊS DE SOCIOLOGIA: sociedade, crise e reconfigurações, 2012, Porto. Anais eletrônicos... Porto, 2012. Disponível em:

〈http://www.aps.pt/vii congresso/papers/finais/PAP0270 ed.pdf> Acesso em: 27 jun. 2018.

BAKHTIN, Mikhail. Estética da criação verbal. São Paulo: Martins Fontes, 1997 [1979].

BOURDIEU, Pierre. A economia das trocas linguísticas. São Paulo: EDUSP, 1996.

CLIFFORD, James. Sobre a autoridade etnográfica. In: CLIFFORD, J. A experiência etnográfica: a antropologia e literatura no séc. XX. Rio de Janeiro: UFRJ, 1998. p. 17-58. 
DOLORIERT, Clair; SAMBROOK, Sally. Ethical confessions of the "I" of autoethnography: the student's dilemma". Qualitative Research in Organizations and Management: an International Journal, v. 4, n.1, p. 27459, 2009. DOI:

<http://dx.doi.org/10.1108/17465640910951435 >.Acessoem: 20 mai. 2019.

ELLIS, Carolyn; BOCHNER, Arthur P. Autoethnography, personal narrative, reflexivity: researcher as subject. In: DENZIN, N.; LINCOLN, Y. (Ed.).Handbook of qualitative research. Sage Pubs, Thousand Oaks, California, 2000.p. 733-768.

ELLIS, Carolyn; ADAMS, Tony E.; BOCHNER, Arthur P. Autoethnography: an overview. Forum Qualitative Sozialforschung / Forum: Qualitative Social Research, v. 12, n. 1, [s.p.], 2011. DOI: <http://dx.doi.org/10.17169/fqs-12.1.1589>. Acesso em: 01 jun. 2019.

ERIKSSON, Thommy. Being native: distance, closeness and doing auto/self-ethnography. ArtMonitor, n. 8, p. 91-100, 2010. Disponível em: <http://hdl.handle.net/2077/24689>. Acesso em: 06 jun. 2018.

FORTIN, Sylvie. Contribuições possíveis da etnografia e da autoetnografia para a pesquisa na prática artística. Tradução: Helena Mello. Revista Cena7, n. 7, p. 77-88, 2009. Disponível em: $\langle$ https://seer.ufrgs.br/cena/article/view/11961/7154>. Acesso em $01 \mathrm{de}$ jun. 2019.

GADAMER, Hans-Georg. Verdade e método II. Tradução: Enio Paulo Giachini. Petrópolis: Vozes, 2002.

GARCEZ, Pedro de Moraes; SCHULZ, Lia. Olhares circunstanciados: etnografia da linguagem e pesquisa em Linguística Aplicada no Brasil. Delta, vol. 31, número especial, p. 1-34, 2015. DOI: <http://dx.doi.org/10.1590/0102-445093806057590158> Acesso em: 17 mar. 2020.

GEE, James P. Situated language and learning: a critique of traditional schooling. New York and London: Routledge, 2004.

GEERTZ, Clifford. A interpretação das culturas. Rio de janeiro: LTC, 2008 [1973]. 
A autoetnografia em pesquisas em Linguística Aplicada...

GREEN, Judith; BLOOME, David. Ethnography and ethnographers of and in education: a situated perspective. In: FLOOD, J.; HEATH, S. B.; LAPP, D. (Ed.). Handbook of research on teaching literacy through the communicative and visual arts. New York: Macmillan Publishers, 2008.p. $1-41$.

HALL, Stuart. A identidade cultural na pós-modernidade. Tradução: Tomaz Tadeu da Silva e Guacira Lopes Louro. Rio de Janeiro: DP\&A, 1998.

JUNIOR, João R. O que é positivismo. 2 ed. São Paulo: Editora Brasiliense, 1983.

KALANTZIS, Mary; COPE, Bill (Ed.). Multiliteracies: literacy learning and the design of social features. London and New York: Routledge, 2000.

KONDER, Leandro. O que é dialética? São Paulo: Editora Brasiliense, 1981.

KRESS, Gunther. Literacy in the new media age. London and New York: Routledge, 2003.

LANKSHEAR, Colin; KNOBEL, Michele. New literacies: everyday practices and classroom learning. Berkshire: Open University Press, 2006.

LUDKE, Menga; ANDRÉ, Marli E. D. A. Pesquisa em educação: abordagens qualitativas. São Paulo, Editora Pedagógica e Universitária, 1986.

MENEZES DE SOUZA, Lynn M. T. Para uma redefinição de letramento crítico: conflito e produção de significação. In: MACIEL, R. F.; ARAUJO, V. A. (Orgs.). Formação de professores de línguas: ampliando perspectivas. Jundiaí: Paco e Littera Editorial, 2011a. p. 128-140.

. O professor de inglês e os letramentos no século XXI: métodos ou ética? In: JORDÃO et al. (Org.). Formação desformatada: práticas com professores de língua inglesa. Campinas, SP: Pontes, 2011b. p. 279-303.

MONTE MÓR, Walkyria. Crítica e letramentos críticos: reflexões preliminares. In: ROCHA, C. H.; MACIEL, R. F. (Orgs.). Lingua estrangeira e formação cidadã: por entre discursos e práticas. Edição ampliada. Coleção: Novas Perspectivas em Linguística Aplicada v. 33. Campinas, SP: Pontes Editores, 2013. p. 31-50. 
. 'Multi', 'trans' e 'plural': discutindo paradigmas. In: TAKAKI,

N. H.; MACIEL R. F. (Orgs.) Letramentos em terra de Paulo Freire.

Campinas, SP: Pontes Editores, 2014. p. 9-21.

Letramentos críticos e expansão de perspectivas: diálogos sobre práticas. In: JORDÃO, C. M.; MARTINEZ, J. R.; MONTE MÓR, W. Letramentos em prática na formação inicial de professores de inglês. Campinas: Pontes Editores, 2018. p. 315-335.

ONO, Fabrício P. T. A formação do formador de professores: uma pesquisa autoetnográfica na área de língua inglesa. 2017, 156f. Tese (Doutorado em Letras) - Faculdade de Filosofia, Letras e Ciências Humanas, Universidade de São Paulo, São Paulo, 2017.

PARDO, Fernando da Silva. Ensino de línguas, letramentos e desenvolvimento crítico na escola pública: observações e autoobservações. 2018, 219f. Tese (Doutorado em Letras) - Faculdade de Filosofia, Letras e Ciências Humanas, Universidade de São Paulo, São Paulo, 2018.

PEREIRA, Maria G. D.; VIEIRA, Amitza T. Autoetnografia em estudos da linguagem e áreas interdisciplinares. Veredas, v. 22, n. 1, 2018. Disponível em: 〈https://www.ufjf.br/revistaveredas/edicoes/2018-9/v-22-no-1/> Acesso em: 17 mar. 2020.

ROCHA, Ana Luiza; ECKERT, Cornelia. Etnografia: saberes e práticas. Iluminuras, v. 9, n. 21, 2008. Não paginado. DOI: <https://doi.org/10.22456/1984-1191.9301> Acesso em: 17 mar. 2020.

SARTRE, Jean-Paul. O existencialismo é um Humanismo. 3 ed. Tradução: Rita Correia Guedes. São Paulo: Abril Cultural, 1987.

SILVA, Roberto B. Interpretações: autobiografia de uma pesquisa sobre letramento literário em língua inglesa. 2011. 215f. Tese (Doutorado em Letras) - Faculdade de Filosofia, Letras e Ciências Humanas, Universidade de São Paulo, São Paulo, 2011.

SOARES, Érika A. C. Letramentos críticos e o uso da língua alvo no ensino de língua inglesa: um olhar autoetnográfico. 2017. 289f. Tese (Doutorado em Estudos Linguísticos) - Faculdade de Letras, Universidade Federal de Minas Gerais, Belo Horizonte, 2017. 
A autoetnografia em pesquisas em Linguística Aplicada...

STARR, Lisa J. The use of autoethnography in educational research: locating who we are in what we do. Canadian Journal for New Scholars in Education, v. 3, n. 1, p. 1-9, June 2010. Disponível em:

<https://journalhosting.ucalgary.ca/index.php/cjnse/article/viewFile/30477/ 24876>. Acesso em: 22 mar. 2019.

VARGHESE, Manka M.; JOHNSTON, Bill. Evangelical Christians and English language teaching. TESOL Quarterly, v.41, p. 5-31, 2007. DOI: <https://doi.org/10.1002/j.1545-7249.2007.tb00038.x >. Acesso em: 20 mai. 2019.

VERSIANI, Daniela B. Autoetnografia: uma alternativa conceitual. Letras de hoje, v.37, n. 4, p. 57-72, dez. 2002. Disponível em:

<http://revistaseletronicas.pucrs.br/fo/ojs/index.php/fale/article/view/14258 >. Acesso em: 01 jun. 2019.

WINDLE, Joel A. Social identity and language ideology: challenging hegemonic visions of English in Brazil. Gragoatá, v. 22, n. 42, Niterói, p. 370-392, 2017. DOI: 〈http://dx.doi.org/10.22409/gragoata.2017n42a894>. Acesso em: 01 jun. 2019.

Recebido em: 12/08/2019 Aceito em: 20/12/2019

Title: Autoethnography in Applied Linguistics research: reflections of the researcher/researched subject 